\title{
The cataphoric use of the indefinite this in spoken narratives
}

\author{
MORTON ANN GERNSBACHER and SUZANNE SHROYER \\ University of Oregon, Eugene, Oregon
}

\begin{abstract}
Are concepts that were introduced with the unstressed, indefinite article this, as opposed to the indefinite $a / a n$, more accessible from listeners' mental representations? Subjects heard and then verbally continued each of a series of informal narratives. The last clause of each narrative introduced a new noun phrase that began with either the indefinite this or the indefinite a/an (e.g., this egg or an egg). When the concepts were introduced with the indefinite this, the subjects referred to them more frequently, often within the first clauses that they produced, and typically via pronouns. In contrast, when the concepts were introduced with a/an, the subjects referred to them less frequently and typically via full noun phrases. Thus, concepts introduced with the indefinite this were more accessible; therefore, the indefinite this appears to operate cataphorically to improve referential access.
\end{abstract}

As speakers speak, listeners build mental representations of the ongoing discourse. Both listeners and speakers benefit if these representations are efficiently constructed. One characteristic of an efficient mental representation is that key concepts are easily accessible.

We propose that speakers use certain devices to mark key concepts-in particular, concepts that might play a pivotal role in the upcoming discourse. We also propose that concepts marked with these devices have a privileged status in listeners' mental representations-in particular, they are more accessible. We will call these devices cataphoric devices. ${ }^{1}$

We envision cataphoric devices as counterparts to anaphoric devices. Anaphoric devices signal that certain concepts have been mentioned previously. Anaphoric devices also improve previously mentioned concepts' accessibility from comprehenders' mental representations. For instance, the anaphoric noun phrase, the criminal, makes the previously mentioned concept, a burglar, more accessible (Dell, McKoon, \& Ratcliff, 1983).

In contrast to anaphoric devices, which signal that certain concepts have previously been mentioned, we propose that cataphoric devices signal that certain concepts might subsequently be rementioned. Thus, anaphoric devices signal backward mention, whereas cataphoric devices signal forward mention. But we propose that cataphoric devices, like anaphoric ones, also improve their concepts' accessibility.

In this paper, we explore a candidate cataphoric device. It is the unstressed, indefinite article this. We investigate

This work was supported by National Science Foundation Grant BNS 85-10096. We thank Carrie Clarke and Kathy Varner for transcribing the subjects' continuations, Ellen Galloway for testing the subjects, and Jan Keenan, Teresa Pantzer, Hill Goldsmith, and an anonymous reviewer for commenting on the manuscript. Please address correspondence to M. A. Gernsbacher, Department of Psychology, University of Oregon, Eugene, OR 97403-1227 or mortong@uoregon.oregon.edu. whether concepts introduced with the indefinite this are more accessible than concepts introduced with the more typical indefinite article $a$. Before describing our experimental investigation, however, we shall further describe the particular device we studied.

\section{THE INDEFINITE THIS}

Most of us are familiar with the indefinite article this; we use it frequently to introduce concepts in jokes, as in "So this man walks into a bar," or "So a man walks into a bar with this parrot on his shoulder." We also use the indefinite this to introduce concepts in narratives or conversations, as illustrated by one of Larson's (1982) cartoon characters, a cocktail waitress recounting the events of a barroom brawl:

1. So then this little sailor dude whips out a can of spinach, this crazy music starts playin', and well, just look at this place. [emphasis ours]

Actually, only the first two thises in (1) are examples of the indefinite this; the third this, in "well, just look at this place," exemplifies the stressed this. The indefinite this differs from both the stressed this and the deictic this (as in "This is a mess," or "Look at this!") because the stressed and deictic thises are definite (Perlman, 1969). According to linguists, a classic test of indefiniteness is occurrence in the existential-there construction. As (2) and (3) demonstrate below, the indefinite this and the indefinite a/an pass this indefiniteness test.

2 . There was this guy in my class last semester.

3 . There was $a$ guy in my class last semester.

But as (4) demonstrates, the definite article the fails.

4. *There was the guy in my class last semester.

The indefinite this is interesting for a couple of reasons. First, it is a relative newcomer to English; Wald (1983) 
suggests that its use dates back only to the late 1930s. Second, the indefinite this occurs considerably more often in informal, spoken, dialects than in formal or written ones, although many prescriptive grammarians dictate that it is unacceptable in any dialect (Prince, 1981).

By definition, the indefinite this, like the indefinite $a / a n$, is used to introduce new concepts into a discourse. ${ }^{2}$ Indeed, of the 243 occurrences of the indefinite this that Prince (1981) observed in Terkel's (1974) book, Working, 242 introduced a distinctly new concept; the only exception was arguably introducing the same lexical form but with a different referent. More interestingly, however, in 209 of the 242 occurrences that Prince (1981) observed, the concept introduced with the indefinite this was referred to again.

This observation was quantified more explicitly by Wright and Givón (1987). They recorded 8- and 10-yearolds telling one another informal stories and jokes. When the children introduced concepts with the indefinite this, they referred to those concepts an average of 5.32 times in the subsequent 10 clauses that they produced; in contrast, when the children introduced concepts with the indefinite $a$, they referred to those concepts an average of only 0.68 times in their next 10 clauses.

These data suggest that concepts introduced with the indefinite this play a pivotal role in the subsequent narrative. Thus, it would behoove speakers if such concepts were established in their listeners' mental representations in a way that they could be referred to easily (in other words, if they were made more accessible). Perhaps they were introduced with the indefinite this, as opposed to the more typical indefinite a/an, in order to improve their accessibility.

Indeed, Prince (1981) suggests that the indefinite this parallels a convention in American Sign Language, in which signers establish an absent third person on their right if that third person is intended to be referred to later. An absent third person who is not intended to be subsequently referred to is not established this way. Thus, this convention in American Sign Language also appears to operate as what we have been calling a cataphoric device.

\section{ARE CONCEPTS INTRODUCED WITH THE INDEFINITE THIS MORE ACCESSIBLE?}

Our question in this research was whether concepts introduced with the indefinite this, as opposed to the indefinite $a$, are more accessible from listeners' mental representations. To answer this question, we conducted the following experiment: We auditorily presented several informal narratives to our subjects, first informing them that at some point in each narrative the narrator would stop talking; when this happened, it was the subjects' job to continue telling the narrative. We constructed our narratives so that the last clause of each one introduced a new noun phrase. We shall refer to those nouns as "critical" nouns. We manipulated whether each critical noun was introduced by the indefinite this or the indefinite $a$. Below is an example experimental narrative.

5. I went to the coast last weekend with Sally. We'd checked the tide schedule ' $n$ we'd planned to arrive at low tide--'cuz I just love beachcombin'. Right off, I found 3 whole sand dollars. So then I started lookin' for agates, but I couldn't find any. Sally was pretty busy too. She found this/an egg ...

We proposed that accessibility would be manifested in our subjects' continuations in three ways: frequency of reference, immediacy of reference, and referential explicitness.

By frequency of reference, we meant simply how often the subjects referred to the critical nouns. Presumably, the more accessible a concept is in a speaker's mental representation, the more frequently he or she will refer to it. If introducing concepts with the indefinite this makes those concepts more accessible in listeners' mental representations, then when our subjects changed from being listeners to speakers-that is, when they continued each narrative-they should have referred more frequently to critical nouns introduced with this than to critical nouns introduced with $a$.

By immediacy of reference, we meant how likely it was that the subjects would immediately refer to the critical nouns. Presumably, the more accessible a concept is in a speaker's mental representation, the more quickly he or she can refer to it. Indeed, numerous descriptive linguistic and experimental psycholinguistic data demonstrate that accessibility-both natural and experimentally induced-strongly predicts initial mention (see reviews by Bock, 1982, 1986; Gernsbacher \& Hargreaves, 1988, in press; Kelly, Bock, \& Keil, 1986). If introducing concepts with the indefinite this makes those concepts more accessible, then when our subjects began their continuations, they should have been more likely to refer immediately to critical nouns introduced with this than to critical nouns introduced with $a$.

By referential explicitness, we meant how likely it was that subjects would refer to the critical nouns with more explicit forms of anaphora, such as noun phrases, as opposed to less explicit forms, such as zero anaphors or pronouns. We proposed that accessibility would be manifested in referential explicitness because referential explicitness is inversely related to focus, foregrounding, and topicality. That is, speakers and writers use less explicit anaphors, such as pronouns, to refer to more focused, foregrounded, or topical concepts, and they use more explicit anaphors, such as noun phrases, to refer to less focused, backgrounded, or peripheral concepts (Chafe, 1974, 1976; Fletcher, 1984, Givón, 1983; MarslenWilson, Levy, \& Tyler, 1982; Sidner, 1983; van Dijk \& Kintsch, 1983).

Presumbly, this relation exists because concepts that are more focused, foregrounded, or topical are more accessible in both the producers' (speakers or writers) and the comprehenders' (listeners or readers) mental represen- 
tations. When one considers anaphors as retrieval cues, this relation makes sense: The more accessible the concept is, the less explicit the retrieval cue needs to be (Gernsbacher, in press). That is why referential explicitness would be inversely related to focus, foregrounding, or topicalization, and why it would manifest accessibility.

If introducing concepts with the indefinite this makes those concepts more accessible, then our subjects should have been more likely to use explicit anaphors to refer to critical nouns introduced with the indefinite this and more explicit anaphors to refer to critical nouns introduced with the indefinite $a$.

To summarize, we investigated three manifestations of accessibility: frequency of reference (how frequently subjects referred to the critical nouns), immediacy of reference (how likely subjects were to immediately refer to the critical nouns), and referential explicitness (how likely subjects were to use more versus less explicit forms of anaphora to refer to the critical nouns).

\section{METHOD}

\section{Subjects}

Forty-five undergraduates at the University of Oregon participated as one means of fulfilling a course requirement. All were native American English speakers.

\section{Materials}

We constructed 20 experimental narratives and 8 filler narratives. They ranged in length from 57 to 153 words, with an average length of 93.7 words. All were written in a very informal, conversational dialect. The 20 experimental narratives were randomly ordered and intermixed with the 8 filler narratives. The purpose of the filler narratives was to camouflage the several this-introduced nouns in the final clauses of the experimental narratives.

All 28 narratives were recorded by a college-aged male who was naive with respect to the experimental hypotheses. Our narrator recorded two tapes: On one tape, half the experimental narratives were recorded in their this-introduced form and the other half were recorded in their $a$-introduced form. On the other tape, the reverse was true. One indication of our narrator's naivete was that he inadvertently recorded two of the experimental narratives in their thisform on both tapes; that is, he failed to attend closely enough to his script. Not realizing this mistake until after collecting the data, we omitted these two narratives from our analyses.

\section{Procedure}

Each subject sat in a soundproofed room during the experiment and heard the prerecorded narratives and instructions over a set of headphones. The subjects were told that they would hear the beginnings of 28 stories, each of which they should complete as they felt the narrator of the stories would have done. Thirty seconds were allowed for each continuation. After $20 \mathrm{sec}$, the subjects heard a single tone. They were to stop talking then, if it was convenient to do so, but if not, they could continue for an additional $10 \mathrm{sec}$, at which time they heard two tones. After the two tones, they were given a 15 -sec break before the next narrative. To get accustomed to the experimental task, the subjects first practiced on two narratives.

\section{RESULTS}

Each subject's continuations of the experimental narratives were transcribed according to the methods of Ochs
(1979). In these transcriptions, clause boundaries were marked on the basis of finite verbs and intonation groups (Chafe, 1980). Then, two judges, who were blind to the subjects' identities and the narratives' experimental conditions (i.e., whether the critical nouns were introduced with this or with $a$ ), scored the transcriptions.

\section{Frequency of Reference}

Our first measure of accessibility consisted of how frequently subjects referred to the critical nouns. We predicted that subjects would refer to the critical nouns more frequently when the critical nouns were introduced with the indefinite this than when they were introduced with the indefinite $a$. To test this prediction, we counted the number of times each subject referred to the critical nouns, excluding false starts, hesitations, or other artifactual repetitions (all of which were rare). We counted pronominal reference, both zero and definite (e.g., " and he walked into the room, and $\theta$ took off his coat"), repeated noun phrase reference ("and the man walked into the room"), and synonymous noun phrase reference ("and the guy walked into the room"').

The subjects did indeed refer to the critical nouns more frequently when they were introduced with this than with $a$. More specifically, when the critical nouns were introduced with this, the subjects referred to them an average of 4.05 times per continuation $(S D=1.16)$; in contrast, when the critical nouns were introduced with $a$, the subjects referred to them only 2.76 times per continuation $(S D=1.14)$. This difference was statistically reliable: $t(44)=6.793, p<.0001$, with the subjects as the unit of analysis, and $t(17)=2.556, p<.02$, with the critical nouns as the unit of analysis. In fact, we observed this difference for 42 of the 45 subjects and 17 of the 18 critical nouns.

The subjects did not, however, simply produce more clauses when the critical nouns were introduced with this rather than $a$; in both cases, they happened to produce the same average number of clauses per continuation, 17.8. Rather, the subjects simply used more of their clauses to refer to the critical nouns when the critical nouns had been introduced with this.

As a striking illustration, below is Subject 3's continuation for the example narrative presented in (5) above. Subject 3 heard this narrative with the critical noun $e g g$ introduced with this. As illustrated below, Subject 3 frequently referred to the critical noun.

6. ' $\mathrm{N}$ it looked like it came from a lizard or something or maybe a turtle, but we couldn't tell if it had hatched or not so we put it back where we found it just in case it was still alive.

In contrast, below is Subject 30's continuation for the same narrative, but Subject 30 heard the narrative with the critical noun $e g g$ introduced with $a$.

7. But what I really wanted to find was a whole crab shell. Y'know you can hardly ever find those. You always find just bits and pieces. It's like someone deliberately comes up 'n crunches 'em all before 'ya get there or somethin'. 


\section{Immediacy of Reference}

Our second measure of accessibility consisted of how quickly subjects referred to the critical nouns. We predicted that the subjects would be more likely to refer to the critical nouns immediately when the nouns were introduced with the indefinite this than when they were introduced with the indefinite $a$. To test this prediction, we examined the first clause that each subject produced when he or she began continuing each narrative. We examined these first clauses to ascertain whether the subjects were more likely to refer to the critical nouns in those very first clauses when the nouns had been introduced with this as opposed to $a$. Again, we counted pronominal reference, repeated noun phrase reference, and synonymous noun phrase reference.

The subjects were indeed more likely to refer to the critical nouns in their very first clauses when the nouns were introduced with this. More specifically, the subjects referred to the critical nouns in $47 \%(S D=16 \%)$ of their first clauses when they were continuing narratives that introduced the nouns with this; in contrast, the subjects referred to the critical nouns in only $34 \%(S D=19 \%)$ of their first clauses when they were continuing narratives that introduced the nouns with $a$. This difference was also statistically reliable: $t(1,44)=4.476, p<.001$, with the subjects as the unit of analysis, and $t(1,17)=2.215$, $p<.05$, with the critical nouns as the unit of analysis.

\section{Referential Explicitness}

Our third measure of accessibility was the subjects choice of anaphoric referent for the critical nouns. Recall that speakers use less explicit anaphors such as pronouns and zero anaphors to refer to more accessible concepts, and they use more explicit anaphors such as noun phrases to refer to less accessible concepts. Therefore, we predicted that the subjects would be more likely to use pronouns and zero anaphors to refer to critical nouns introduced with the indefinite this. In contrast, we predicted that the subjects would be more likely to use full noun phrases to refer to critical nouns introduced with the indefinite $a$.

To test this prediction, we attended only to those continuations in which the subjects did in fact refer to the critical nouns. And in those continuations, we attended only to the subjects' first references to the critical nouns (since subsequent references are biased toward being less explicit). There were 533 first references; 376 were made with pronouns and zero anaphors (less explicit anaphors), and 177 were made with noun phrases (more explicit anaphors).

The subjects were indeed more likely to use less explicit anaphors to refer to the critical nouns when the nouns had been introduced with this. More specifically, of the 376 references made with pronouns and zero anaphors, $57 \%$ were references to this-introduced nouns, and the remaining $43 \%$ were references to $a$-introduced nouns. In contrast, the subjects were more likely to use more explicit anaphors to refer to the critical nouns when they were introduced with $a$. More specifically, of the 177 references made with noun phrases, $54 \%$ were to $a$-introduced nouns and the remaining $46 \%$ were to thisintroduced nouns. Thus, the subjects used less explicit anaphors to refer to this-introduced nouns and more explicit anaphors to refer to $a$-introduced nouns. This association statistically departed from chance: $\chi^{2}(1)=6.014$. $p<.013$.

\section{DISCUSSION}

To summarize our results, we found that introducing nouns with the indefinite this, as opposed to the indefinite a/an, greatly affected our subjects' continuations: When the nouns were introduced with this, the subjects referred to them more frequently, often within the first clauses that they produced, and typically via less explicit anaphors like pronouns. In contrast, when the nouns were introduced with $a$, the subjects referred to them less frequently, and typically via more explicit anaphors such as full noun phrases.

These data suggest that listeners are indeed sensitive to the rapidly developing use of the indefinite this, and that concepts introduced with the indefinite this are more accessible from listeners' mental representations. In this way, the indefinite this operates as what we are calling a cataphoric device.

Another device that might work cataphorically in spoken English is spoken stress. Initial phonemes are recognized faster when they begin words that carry their sentences' stress (Cutler, 1976; Cutler \& Foss, 1977; Shields, McHugh, \& Martin, 1974), and stressed words are presumed to signal information focus (Bock \& Mazella, 1983). Thus, spoken stress seems like a good candidate for a cataphoric device. ${ }^{3}$

How do cataphoric devices work? What cognitive mechanisms mediate their effects? Perhaps the same cognitive mechanisms that improve referential access via anaphoric devices improve referential access via cataphoric devices. We have identified two mechanisms that improve referential access via anaphora (Gernsbacher, in press). They are enhancement and suppression. Enhancement increases the activation level of the rementioned concept's mental representation, and suppression decreases or dampens the activation of other concepts' representations. Because enhancement boosts the activation of the rementioned concept, and because suppression dampens the activation of other concepts, the net effect of both mechanisms is that the anaphorically mentioned concept is activated at a different level than other concepts are.

Cataphoric devices might also use these two mechanisms to increase the accessibility of cataphorically introduced concepts. Cataphoric devices might improve their concepts' accessibility by enhancing or boosting the activation of those concepts. Or cataphoric devices might improve their concepts' accessibility by suppressing the activation of other concepts. We are currently exploring these possibilities. 


\section{REFERENCES}

Bock, J. K. (1982). Toward a cognitive psychology of syntax: Information processing contributions to sentence formulation. Psychological Review, 189, 1-47.

Bock, J. K. (1986). Meaning, sound, and syntax: Lexical priming in sentence production. Joumal of Experimental Psychology: Learning, Memory, \& Cognition, 112, 575-586.

Bock, J. K., \& MAZELLA, J. R. (1983). Intonational marking of given and new information: Some consequences for comprehension. Memory \& Cognition, 11, 64-76.

Chafe, W. L. (1974). Language and consciousness. Language, 50, 111-133.

Chafe, W. L. (1976). Givenness, contrastiveness, definiteness, subjects, topics, and points of view. In C. N. Li (Ed.), Subject and topic (pp. 25-56). New York: Academic Press.

Chafe, W. L. (Ed.) (1980). The pear stories: Cognitive, cultural, and linguistic aspects of narrative production. Norwood, NJ: Ablex.

CHAFE, W. L. (1987). Cognitive constraints on information flow. In R. S. Tomlin (Ed.), Coherence and grounding in discourse. Amsterdam: Benjamins.

Clark, H. H., \& Marshall, C. R. (1981). Definite reference and mutual knowledge. In A. Joshi, B. Webber, \& I. Sag (Eds.), Elements of discourse understanding (pp. 10-63). Cambridge, England: Cambridge University Press.

Cutler, A. (1976). Phoneme-monitoring reaction time as a function of preceding intonation contour. Perception \& Psychophysics, 20, 55-60.

Cutler, A., \& Foss, D. J. (1977). On the role of sentence stress in sentence comprehension. Language \& Speech, 20, 1-10.

Dell, G. S., McKoon, G., \& RatclifF, R. (1983). The activation of antecedent information during the processing of anaphoric reference in reading. Journal of Verbal Learning \& Verbal Behavior, 22 , 121-132.

FLETCHER, C. R. (1984). Markedness and topic continuity in discourse processing. Journal of Verbal Learning \& Verbal Behavior, 23, 487-493.

Gernsbacher, M. A. (in press). Mechanisms that improve referential access. Cognition.

Gernsbacher, M. A., \& Hargreaves, D. (1988). Accessing sentence participants: The advantage of first mention. Journal of Memory \& Language, 27, 699-717.

Gernsbacher, M. A., Hargreaves, D. (in press). The privileged position of first mention: A structure building account. Typological Studies in Language.

Givón, T. (Ed.) (1983). Topic continuity in discourse: A quantitative cross-language study. Amsterdam: Benjamins.

Gıvón, T. (1985). The pragmatics of referentiality. In D. Schiffrin (Ed.), Meaning, form, and use in context. Washington, DC: Georgetown University Press.

Kelly, M. H., BoCK, J. K., \& KeIL, F. C. (1986). Prototypicality in a linguistic context: Effects on sentence structure. Journal of Memory \& Language, $25,59-74$.
LARSON, G. (1982). The far side. New York: Andrews, McMeel, \& Parker.

Marslen-Wilson, W., Levy, E., \& Tyler, L. K. (1982). Producing interpretable discourse: The establishment and maintenance of reference. In R. J. Jarvella \& W. Klein (Eds.), Speech, place and action (pp. 339-378). Chichester, England: Wiley.

Ochs, E. (1979). Planned and unplanned discourse. In T. Givón (Ed.), Syntax and semantics (Vol. 12). New York: Academic Press.

Perlman, A. (1969). 'This' as a third article in American English. American Speech, 44, 76-80.

Prunce, E. (1981). On the inferencing of indefinite-this NPs. In A. Joshi, B. Webber, \& I. Sag (Eds.), Elements of discourse understanding (pp. 231-250). Cambridge, England: Cambridge University Press.

QUiRK, R., \& GREENBaUm, S. (1976). A concise grammer of contemporary English (5th ed.). New York: Harcourt, Brace, Jovanovich.

Shields, J. L., McHugh, A., Martin, G. (1974). Reaction time to phoneme targets as a function of rhythmic cues in continuous speech. Journal of Experimental Psychology, 102, 250-255.

Sidner, C. L. (1983). Focusing and discourse. Discourse Processes, 6, $107-130$.

TERKEL, S. (1974). Working. New York: Avon.

VAN DiJK, T., KINTSCH, W. (1983). Strategies of discourse comprehension. New York: Academic Press.

WALD, B. (1983). Referents and topic within and across discourse units: Observations from current vernacular English. In S. Klien-Andreu (Ed.), Discourse perspectives on syntax (pp. 91-116). New York: Academic Press.

WrIGHT, S., \& Givón, T. (1987). The pragmatics of indefinite reference: Quantified text-based studies. Studies in Language, 11, 1-33.

\section{NOTES}

1. We are using the term cataphoric in the sense that linguists do. For instance, Quirk and Greenbaum (1976, p. 302) write that certain expressions "point back (anaphoric) or forward (cataphoric) in discourse." Cataphoric devices include, but are broader than, cataphoric pronouns. Their communality lies in the connotation of cataphoric as "forward."

2. A few culturally shared or contextually unique concepts are introduced with the definite article--for example, the sun, the President, or "I walked into the house, and the stereo was blaring" (Chafe, 1987; Clark \& Marshall, 1981; Givón, 1985).

3. It is possible that concepts introduced with the indefinite this receive more spoken stress than concepts introduced with the indefinite a/an. However, the duration (the prominent feature of contrastive stress) of the critical nouns did not differ reliably when they were preceded by this versus $a$.

(Manuscript received June 24, 1988; revision accepted for publication January 18, 1989.) 